\begin{tabular}{|l|l|l|l|l|l} 
Revista Praxis & ISSN: $1657-4915$ & Vol. 14 & No. 1 & 7 - 8 & enero - junio de 2018 \\
\hline
\end{tabular}

DOI: http://dx.doi.org/10.21676/23897856.2713

\title{
EDITORIAL
}

\section{HACIA UNA RESIGNIFICACIÓN DEL PERFIL PROFESIONAL DEL PROFESOR EN LA ESCUELA COLOMBIANA}

\section{Jorge Mario Ortega Iglesias ${ }^{1}$}

La apremiante necesidad por mejorar los niveles de calidad educativa en el concierto nacional y, en particular, por visibilizarnos positivamente ante los diferentes sistemas de medición de procesos de calidad educativa en el contexto internacional, ha traído consigo diferentes desafíos al sistema educativo colombiano. Tal condición ha promovido el diseño de políticas públicas, tendientes, entre otros componentes, a la reconfiguración curricular de los establecimientos educativos, el diseño de un sistema estandarizado y articulado de evaluación de los aprendizajes en todos los niveles de formación $\mathrm{y}$, especialmente, al posicionamiento de un tipo de sujeto por formar; un sujeto competente para los desafíos del mundo contemporáneo.

Este escenario nacional, mediado inevitablemente por lineamientos de índole internacional, plantea un reto mayor en tanto el papel y las características que definen al profesor para desenvolverse en dicho escenario. Por lo que es necesario preguntase: ¿cuál es el perfil que debe tener el profesor en la escuela colombiana? Es, sin duda alguna, un punto muy importante que merece un espacio de reflexión continua.

En tal sentido, la recuperación de la imagen y el papel protagónico del profesor en la escuela colombiana y, en especial, a partir del tipo de conocimiento disciplinar que produce y enseña (Ortega, 2017) constituye un tema pendiente en la agenda nacional que decante en la necesidad de configurar un perfil profesional del maestro a la luz de los retos, desafíos y momento histórico que atraviesa nuestro país. Temas de amplia relevancia social como la paz, el fenómeno del cambio climático que afecta diferentes ecosistemas en el territorio nacional, la corrupción en todas sus manifestaciones, las grandes movilizaciones y tendencias de opinión que internet y que las redes sociales manejan, hacen parte de una variedad de componentes que dialogan directa e indirectamente con el currículum escolar y que requieren ser analizados de manera constante a la luz del papel que tiene el profesor para la formación de sujetos. De ahí la importancia de educar para transformar la realidad circundante, donde los sujetos puedan formase a partir del reconocimiento de las problemáticas de su contexto, pero que, adicionalmente, cuenten con habilidades suficientes para intervenirlas y mejorarlas.

Estos elementos dejan en evidencia que la formación por competencias, habilidades, destrezas, actitudes, y demás componentes que posibiliten el quehacer en contexto de nuestros estudiantes, conforman una tendencia apremiante que va desde la formulación de políticas públicas a nivel nacional, hasta el diseño de currículos y sistemas de evaluación en las instituciones educativas; lo que hace posible la formación de un sujeto que pueda desenvolverse con éxito ante los desafíos que su comunidad y lugar de origen proponen, esto sin mencionar las habilidades de índole intercultural, idiomáticas, informacional y mediáticas que nuestros estudiantes deben tener para desplazarse en el marco internacional.

Situar este proyecto de envergadura económica, política y social, a pesar de sus resistencias y miradas alternativas, merece una deconstrucción permanente hacia el establecimiento de una ruta de desarrollo profesional del profesorado que condense una mirada local con perspectiva

${ }^{1}$ Editor - Universidad del Magdalena, Santa Marta, Colombia. Correo electrónico: jortegai@unimagdalena.edu.co ORCID: 0000-0002-6458-3650 
nacional e internacional, por lo que plantear un perfil o perfiles del profesor en la escuela colombiana es una tarea necesaria y urgente ante los desafíos que el proyecto de formación por competencia ha instalado desde hace más de una década.

Esta posibilidad de formación implica la necesidad de reflexionar y crear propuestas de desarrollo profesional del profesorado, pensadas incluso como un proceso continuo y articulado desde la formación inicial (Niemi, 2015; Ponte, 2012), por lo que el éxito de formar por competencias no solo radica en cuestionarnos qué tan competentes son nuestros estudiantes, sino también nuestros maestros para formar sujetos competentes. Lo anterior sin mencionar que para formar maestros competentes, también debemos preguntarnos por nuestro sistema educativo para provocar la generación de estas competencias tanto en los maestros como estudiantes y distintos actores que participan en el proceso de escolarización. Es, pues, una cadena de cuestionamientos que lleva de la mano un compromiso articulado cuya visión de escuela en su conjunto, con todos los actores sociales comprometidos, merece la pena tener.

Pensar el perfil del profesor que requiere el contexto nacional amerita una atención mayor dadas las complejidades socioeconómicas y los procesos de calidad educativa que el Estado colombiano propone a la luz del tipo de sujeto se desea formar. Pero, más importante aun, instituye el hecho de repensar el perfil del profesor que educa al tipo de sujeto que requieren nuestras sociedades. De esta manera, en el ámbito de la profesión docente es necesario seguir cuestionando con profunda reflexión sobre: ¿quién es el profesor que educa en nuestras escuelas?, ¿cuáles son sus necesidades de formación?, ¿están preparados nuestros maestros para contribuir con la formación de sujetos de manera coherente y acertada ante las necesidades de su entorno? Estos interrogantes merecen un efecto de onda de resonancia cultural, para que nos haga reflexionar arduamente ante los cambios inevitables que acontecen en nuestro país y el mundo contemporáneo.

\section{REFERENCIAS BIBLIOGRÁFICAS}

Niemi, H. (2015). Desarrollo profesional docente en Finlandia: Hacia un enfoque más holístico (trad. al castellano de C. Marín). Psychology, Society and Education, 7(3), 387-404. [V.O.: Teacher professional development in Finland: Towards a more holistic approach. Psychology, Society and Education, 7(3), 279-294].

Ortega, J. M. (2017). Conocimiento escolar y conocimiento "disciplinar" del profesor: algunas reflexiones sobre la participación del profesor en la construcción y enseñanza del contenido asociado a las disciplinas escolares. Folios, (45), 87-102. https://doi.org/10.17227/01234 870.45 folios 87.102

Ponte, J. (2012). Estudiando el conocimiento y el desarrollo profesional del profesorado de matemáticas. En N. Planas (Comp.), Teoría, crítica y práctica de la educación matemática (pp. 83-98). Barcelona, España: Grao. 